\title{
MODEL KEGIATAN KEPRAMUKAAN BERBASIS PARADIGMA INTEGRASI DI SD ISLAM QUR'ANI BANDA ACEH
}

\author{
Zikraul Husna, Muqowim, Dibrina Raseuki Ginting, Veni Veronika \\ Siregar, Rif'atul Fadilah \\ Surel: 20204081011@student.uin-suka.ac.id
}

\begin{abstract}
Scouting activities are external activities that take advantage of teaching arrangements and adjustments for each scout section that has noble character. This research means directing and familiarizing every part of the scouts to have a sensible personality. Reconnaissance exercises are very successful in instilling character in the young children of the class. The reason for holding this exam is to decide on the technique of observing character values at SD Islam Al-Qur'an Banda Aceh. This examination uses an interesting subjective where data collection is completed by interviews, observation and documentation. The consequences of learning exercises that contain character appreciation and have a positive impact are directed through the level of consistency of adjustment. The framework between the training program and students is completed in a coordinated manner. So often reconnaissance drills are directed through constant adjustments.
\end{abstract}

Keywords: Scouting Activities, Elementary School, Integration

\begin{abstract}
ABSTRAK
Kegiatan pramuka adalah aktivitas luar yang memanfaatkan pengaturan pengajaran dan penyesuaian setiap bagian pramuka yang memiliki orang berakhlak mulia. Riset ini berarti mengarahkan dan membiasakan setiap bagian pramuka agar memiliki pribadi yang berakal. Latihan pengintaian sangat berhasil dalam menanamkan karakter pada anak-anak muda kelas. Alasan diadakannya penelitian ini adalah untuk memutuskan teknik latihan observasi nilai karakter di SD Islam Al-Qur'an Banda Aceh. Pemeriksaan ini menggunakan subyektif yang menarik dimana pengumpulan data diselesaikan dengan wawancara, observasi dan dokumentasi. Konsekuensi dari latihan-latihan pembelajaran yang mengandung penghayatan karakter dan berdampak positif diarahkan melalui tingkat konsistensi penyesuaian. Kerangka kerja antara program latihan dan siswa diselesaikan secara terkoordinasi. Begitu sering latihan pengintaian diarahkan melalui penyesuaian terus-menerus.
\end{abstract}

Kata Kunci: Kegiatan Pramuka, Sekolah Dasar, Integrasi

\section{PENDAHULUAN}

Pramuka adalah kependekan dari Praja Muda Karana. Survei menurut Lodr Baden Powell adalah bahwa pramuka bukanlah ilmu yang harus dikonsentrasikan terusmenerus juga bukan kumpulan pelajaran dan tulisan dari sebuah buku melainkan permainan di alam terbuka yang berisi pendidikan. (Sunardi, 2014). Menurut KBBI adalah sebuah aktivitas bagi kaum muda yang mendidik para anggotanya dalam berbagai keterampilan, disiplin, wibawa, saling memfasilitasi, dan sebagainya. Ekstrakurikuler pramuka diperhitungkan sebagai kegiatan 
pelengkap metode pendidikan di kelas. Permendikbud nomor enam puluh tiga tahun 2014 tentang pendidikan pengintaian sebagai kegiatan wajib, bahwa: "Info pendidikan pengintaian 2013 siap sebagai kegiatan wajib (Permendikbud, 2014). Artinya, latihan pramuka merupakan latihan tingkat tinggi yang sengaja diperjuangkan sebagai wahana untuk membentengi wawasan dan kemampuan mental sosial-sosial dalam data tahun 2013 yang secara psikopedagogis sadar dengan mentalitas dan kesempatan kemampuan dalam latihan pengintaian pramuka (Luthviyani,I., R. Setianingsih, E., S. \& Handayani, D., 2019). Pembinaan Pramuka dibingkai untuk memberikan teknik pembentukan kepribadian Pramuka, kemampuan dasar, dan pribadi yang terhormat melalui penghayatan dan pengamalan nilai-nilai ujung tombak berdasarkan kode etik Pramuka dan mengabaikan standar esensial metodologi rencana dan rencana.

Zaman kini menjadi zaman yang sangat canggih dikarenakan semua informasi dapat didapatkan melalui internet baik info yang positif maupun negative hal tesebut berdampak pada karakter anak dan perlunya ada pembinaan karakter dan pembiasaan untuk merubah sikap kea rah yang lebih baik. Pendidikan karakter adalah terciptanya tatanan tempat belajar yang membantu murid dalam mengembangkan etika, tanggung jawab melalui keteladanan, dan pengajaran budi pekerti melalui nilai-nilai yang luas (Santika, 2020).

Karakter merupakan dasar dan sebagai tatanan dalam mengeksplorasi kehidupan khas, korespondensi, fonetik sinkronis dan perilaku yang mencerminkan sebagai penduduk terpuji. Harus ada penghiburan penuh untuk menumbuhkan kemampuan peneliti dan memahami karakter secara mandiri.

Nilai-nilai Pramuka dalam Menjelajah telah bekerja pada seluruh warga negara yang harus ditanamkan pada siswa. Ada nilainilai kekeluargaan dan harta benda dengan latihan misi pengawasan, sebagai berikut: 1) karakter nonmainstream; 2) sikap yang sah; 3) disposisi resistensi; 4) mentalitas disiplin; 5) mentalitas kerja yang sulit; 6) disposisi imajinatif; 7) disposisi bebas; 8) mentalitas penguasa mayoritas, 9) watak kepentingan, 10) sikap jiwa masyarakat, 11) watak pengabdian; 12) mentalitas penghargaan karakter; 13) Orang yang ramah/terbuka; 14) orang yang tenang; 15) memahami mentalitas; 16) mentalitas peduli sekitar; 17) sikap pertimbangan sosial; dan 18) mentalitas kewajiban (Hudiyono, 2012).

Berdasarkan hasil wawancara dengan siswa di tempat tersebut siswa sangat tertarik dalam mengikuti kegiatan pramuka dan sekolah juga mendukung dalam pelaksanaannya, saat kegiatan pramuka berlangsung guru mengaitkan materi dengan kegiatan sehari-hari dan juga mengajarkan karakter yang baik yang 
harus dilakukan anak-anak tersebut dimanapun mereka berada.

\section{METODE PENELITIAN}

Strategi ilmiah yang digunakan dalam riset ini adalah penyelidikan subyektif, pemeriksaan subyektif adalah penyelidikan yang berarti menangkap kemajuan-kemajuan apa yang dikuasai oleh subyek penelitian seperti tingkah laku, kearifan, inspirasi, aktivitas. Komprehensif dan dengan strategi memukau dalam gaya kata-kata dan bahasa, dalam pengaturan reguler yang sangat luar biasa dan dengan menggunakan cara normal yang berbeda (Moleong 2017).

Analisis ini termasuk dalam ragam pengetahuan kualitatif, khususnya eksploitasi pengetahuan kata-kata atau deskripsi dari fakta atau fenomena yang sedang ditentukan. Dalam analisis kualitatif, instrumen atau alat analisisnya adalah ilmuwan itu sendiri, dalam penelitian ini terdapat 2 responden yang relevan dengan subjek penelitian Pembina pramuka di SD Islam Qur'ani Banda Aceh. Pada penelitian ini teknik pengumpulan data yang digunakan meliputi cara triangulasi yakni observasi, dokumentasi, dan wawancara (Sugiyono 2019). Penelitian ini dilaksanakan antara bulan Mei-Juni 2021 di SD Islam Qur'ani Banda Aceh.

\section{HASIL PENELITIAN DAN PEMBAHASAN}

- Pelaksanaan Kegiatan Kepramukaan Kegiatan pramuka di sekolah tersebut dilaksanakan sekali dalam semingggu yaitu pada hari kamis siang setelah melakukan solat zuhur yang mana kegiatan tersebut hanya diterapkan pada murid kelas 5 saja karena kegiatan ini baru mulai di terapkan di tahun 2020. Kegiatan pramuka ini terdapat beberapa disiplin ketika pelaksanaannya diantaranya yaitu menggunakan seragam lengkap baik itu dari topi, cikal, peluit, dan lain-lain. Gerakan ini bermaksud membentuk setiap bagian agar memiliki etika yang dapat diandalkan, bertaqwa, terhormat, tabah, bereputasi, terkendali, dan menjaga kualitas terhormat negara.

Ketika kegiatan pramuka berlangsung siswa diajarkan tentang dasar kepramukaan fungsi kepramukaan, dasa darma, tri satya, beberapa sandi, semaphore, morse, dan hal lainnya. Pembina mengajarkan materi dan langsung mencontohkan gerakannya.

\section{- Nilai Karakter}

Temuan riset tentang nilai karakter murid berjalan dengan lancer. Kegiatan pramuka berlaku mengikuti pembelajaran sambil menyimak peristiwa pola pikir siswa dalam menerima pembelajaran dari materi dan tugas yang diberikan oleh pembimbing siaga. hal ini dapat dibuktikan dengan hasil riset kegiatan pramuka, klarifikasi selanjutnya adalah sebagai berikut:

Sikap siswa yang tegas menunjukkan sikap tunduk dalam menyelesaikan kewajiban masingmasing ummat. Misalnya, sembayang zhuhur berjamaah di koridor sekolah, 
mencium tangan guru sebagai isyarat yang layak, terus-menerus bersyukur atas keanggunan yang diberikan oleh Tuhan Yang Maha Kuasa dan hidup berdampingan dengan para sahabat. Hal ini ditegaskan setiap hari membaca Al-Qur'an dan Asmaul Husna ketika berkonsentrasi di kelas dan berdoa bersama.

\section{Sikap jujur}

Sikap yang jujur tercermin dari siswa yang kebobolan ketika melakukan kesalahan, mengurus tugas dari pembimbing dan pendidik yang memberikan tugas di sekolah, kebobolan ketika mereka datang lebih lambat dari yang diharapkan dan bertanggung jawab atas keputusan mereka. Siswa juga ditanggapi dengan tulus ketika mengetahui apakah mereka merasa nyaman atau tidak saat melakukan latihan Eksplorasi.

\section{Sikap Disiplin}

Sikap Orang ini muncul dari premis senang tanpa dorongan untuk tertarik pada gerakan ini. Pembina Pramuka melatih siswa agar terbiasa mengajar, misalnya hadir sesuai jadwal, membentuk barisan sebelum masuk kelas, melakukan kewajiban piket dan berpakaian rapi saat menyelesaikan latihan Pramuka. Tindakan ini ditunjukkan ketika latihan Eksplorasi dilakukan dengan cara yang disengaja dan terlatih.

\section{Karakter Kreatif}

Orang ini, mentor memberikan tugas kepada siswa untuk membuat nyanyian Pramuka untuk setiap kelompok dengan tujuan agar nantinya dapat dikemas dengan menarik dan menyenangkan bagi siswa. Keuntungan dalam desain deduksi siswa dalam memberikan kata-kata yang akan digunakan sebagai nyanyian/yel-yel.

\section{Karakter Tanggung Jawab}

Hal ini terlihat ketika pramuka menjalankan kewajiban dan komitmen yang diberikan oleh pembimbing. Selama menjadi ketua kelompok untuk menerima temanteman yang dinamis dalam latihan, menyelesaikan tugas sesuai dengan waktu yang diberikan dan menjaga amanah.

\section{Sikap Peduli sekitar}

Sosok ini terlihat dan terefleksikan dalam budaya alam di sekolah tersebut, khususnya dalam mewujudkan komitmen melalui piket membersihkan kelas, membersihkan saluran air, dan membuang sampah pada tempatnya. Para mentor melatih siswa untuk mengikuti dan menjaga iklim sekolah seperti merawat tanaman, menjaga kebersihan individu dan mencegah episode infeksi.

\section{Sikap Peduli Sosial}

Sikap ini dipersiapkan dan dididik untuk membantu teman-teman yang menghadapi tantangan atau bencana, peduli pada orang lain, tertarik pada pekerjaan sekolah dan ketika membuat biaya pendidikan yang berencana untuk secara tegas 
mempengaruhi siswa tentang fokus pada orang lain yang kurang beruntung. Siswa tidak memisahkan, semua teman dipeluk dan mudah untuk hidup berdampingan.

\section{Sikap Mandiri}

Kemandirian tercermin dalam kegiatan siswa, khususnya mengerjakan tugas-tugas yang diberikan oleh pembina pramuka jika masih lajang, memakai pakaian sendiri, mengendalikan perasaan, terbiasa dengan hal-hal yang bermanfaat dan suka menabung. Tindakan Mengeksplorasi nilai-nilai pribadi yang mandiri secara tegas mempengaruhi siswa untuk mengarahkan kebutuhan dan penyesuaian mereka sendiri.

\section{Sikap Kompak}

Orang ini terlihat ketika siswa mengerjakan sesuatu bersama-sama, misalnya ketika membuat nyanyian untuk membuat tenda ketika ada acara perkemahan yang diadakan oleh sekolah.

\section{Pembahasan}

\section{Menjelajahi}

sekolah

mendorong siswa untuk menyelidiki pengembangan diri untuk menjadi individu yang seutuhnya. Untuk mencapai tujuan ini, Exploring menciptakan ruang kemajuan yang menggabungkan pergantian peristiwa yang mendalam, antusias, sosial, ilmiah dan aktual. Setiap daerah kemajuan memiliki kemampuan terakhir yang harus dicapai. Keterampilan-keterampilan ini diharapkan dapat memberikan arah pada pengembangan diri, pengaturan arah potensi sesuai usia dan sifat individu.

Para penulis menerima bahwa nilai karakter seperti tegas, tulus, terkendali, imajinatif, penuh perhatian, pertimbangan alami, pertimbangan sosial, dan otonomi dapat dibentuk melalui latihan eksplorasi. Kenyataan di lapangan adalah bahwa siswa masih buruk dalam mengatur dan mengubah harga diri seseorang. Hal ini dibuktikan ketika siswa diremehkan oleh temannya, mengabaikan tugas dari guru, membuang sampah sembarangan, pekerjaan yang tidak penting, dan lain sebagainya.ramuka adalah individu-individu dari perkembangan eksplorasi yang terdiri dari individu-individu muda, menjadi siswa khusus pada cadangan, penggalang, Pelaksana dan penjaga gerbang. Tingkatan dalam bereksplorasi dikendalikan oleh usia individunya, misalnya usia kumpul 710 tahun dikenal sebagai pramuka cadangan. Perkumpulan usia 11-15 tahun ini dikenal dengan sebutan Pramuka Pembangkit. Pengumpulan usia 16-20 tahun ini dikenal dengan istilah pramuka otorisasi. Kumpulan usia 21-25 tahun ini dikenal dengan nama Pendega Pramuka (Jayanti 2016).

Alasan Pembinaan Pramuka
adalah untuk membingkai setiap
pramuka agar memiliki karakter
percaya diri, pengabdian, orang
terhormat, jiwa energik, jujur,
terkendali, menjaga kualitas


kehormatan negara dan memiliki kemampuan mendasar sebagai kerangka negara dalam memelihara dan membangun Negara Kesatuan Republik Indonesia. Indonesia, mengamalkan Pancasila, dan menjaga iklim (Afdal and Widodo 2020).

Paradigma integrasi ada beberapa mazhab signifikan yang sesuai dengan hipotesis informasi, khususnya ada tiga model kerangka intuisi dalam Islam. Ketiga model pemikiran tersebut menggabungkan bayani, burhani, dan irfani. Kami akan menggunakan tiga model deduksi ini untuk menggabungkan studi instruksi Islam dengan pelatihan eksplorasi seperti yang digambarkan sebelumnya.

\section{Bayani}

Bayani adalah teknik berspekulasi yang bergantung pada kandungan Al-Qur'an dan Al Hadits (Khoiruddin 2016). Ada dua kode kehormatan untuk pramuka cadangan, seperti yang diungkapkan dalam segmen sebelumnya, secara spesifik, dwi satya dan dwi dharma. Kode kehormatan akan diperluas melalui model pemikiran Bayani. Jaminan pramuka cadangan yang terkandung dalam dwi satya ada dua, yaitu: yang utama tidak main-main dalam menunaikan kewajibannya kepada Tuhan Yang Maha Esa, Provinsi Kesatuan Indonesia, dan mengikuti tata krama keluarga. Tiga segmen yang terkandung dalam substansi dwi satya pertama juga diungkapkan dalam Al-Qur'an cukup lama. Allah berfirman dalam Al Qur'an Surat AnNisa ayat 1.

2. Burhani

Burhani adalah dalang yang berpendapat bahwa sumber informasi adalah akal (Purwati and Devi 2020). Di dalam kegiatan pramuka burhani ini dapat dikatakan praktek arau realitas. Seperti saat melakukan materi semaphore atau morse maka di dalamnya harus dilakukan dengan cara praktik.

\section{Irfani}

Irfani merupakan berkaitan dengan pengetahuan yang diperoleh secara pengolahan batin yang diungkapkan secara logis (Tabrani 2015), atau di sisi lain pada akhirnya keuntungan dari informasi yang telah dipelajari. Kelebihan renungan dwi satya dan dwi dharma adalah siap dan konsisten memiliki keyakinan dan rasa takut kepada Allah SWT, mencetak pramuka yang siap tunduk pada pedoman yang ada dalam keluarga, menyusun karakter pemuda negara yang teguh dalam pendirian. posisi mereka dan tidak pernah menyerah.

\section{SIMPULAN}

Dilihat dari konsekuensi riset yang telah dilakukan, cenderung beralasan bahwa tugas pembimbing sebagai kaki tangan peningkatan karakter bekerja melalui eksplorasi harus benar-benar dijunjung tinggi oleh sekolah dan wali murid. Karena ini adalah salah satu faktor penting dalam mempengaruhi cara menuju penanaman orang tersebut. Latihan 
eksplorasi mengandung nilai karakter di dalamnya dan dibawakan secara tepat melalui penyesuaian dan model. Pelaksanaan latihan Eksplorasi diatur, dengan organisasi yang baik dan metode budidaya yang baik sehingga penyampaian materi kepada siswa tercapai.

Efeknya mempengaruhi kecenderungan siswa. Pemberian gambaran mentalitas merupakan bagian dari kerangka Among untuk menjadi sosok yang mampu menumbuhkan kemampuan individuindividu dari Siaga Pramuka Kelas V. Model yang diharapkan adalah memberikan gambaran tentang watak yang baik yang mengandung penghayatan karakter. Memberikan contoh mentalitas yang baik kepada siswa adalah salah satu bagian dari kerangka kerja antara. Kerangka kerja antara biasanya digunakan dalam pembelajaran latihan eksplorasi untuk membentuk siswa menjadi mandiri, terkendali, dan bebas dalam hubungan yang setara antara orang-orang.

Penyesuaian dilakukan secara konsisten dan persisten. Contoh yang baik memberikan model dengan tujuan agar siswa nantinya bertindak sesuai nilai karakter secara optimal. Penyesuaian dan model ini dilakukan dengan sengaja tanpa tekanan yang nantinya akan diakui sebagai salah satu bentuk bagian dalam membentuk individu agar dapat diterima. Contoh pelaksanaannya adalah cara hidup antre saat mandi, membeli jajan, cara hidup mengontrol datang tepat waktu, memperhatikan

\section{DAFTAR RUJUKAN}

Afdal, and Heri Widodo. 2020. "Analisis Pelaksanaan Kegiatan Pramuka Di Sd Negeri 004 Samarinda Utara Tahun 2019." PENDAS MAHAKAM: Jurnal Pendidikan Dasar 4 (2): 68-81. https://doi.org/10.24903/pm.v4i2. 399.

Jayanti. 2016. Buku Lengkap Pramuka. Jakarta: Media Ilmu Abadi.

Khoiruddin, Nasution. 2016. Pengantar Studi Islam. Jakarta: Raja Grafindo Perkasa.

Moleong. 2017. Metodelogi Penelitian Kualitatif. Bandung: Remaja Rosda Karya.

Purwati, Yayuk, and Aulia Diana Devi. 2020. "Konsep Penalaran Bayani, Irfani Dan Burhani Pada Pembelajaran Aqidah Ahlak Dalam Pendidikan Islam.” MADROSATUNA: Jurnal Pendidikan Guru Madrasah Ibtidaiyah $3 \quad$ (2): $\quad 89-97$. https://doi.org/10.47971/mjpgmi. v3i2.275.

Sugiyono. 2019. Metode Penelitian Pendidikan (Kuantitatif, Kualitatif, Kombinasi, $R \& D$ Dan Penelitian Pendidikan. Edited by Nuryanto Apri. 3rd ed. Bandung: Alfabeta.

Tabrani, Za. 2015. Persuit Epistimology Of Islamic Studies. Yogyakarta: Penerbit Ombak (Anggota IKAPI). 